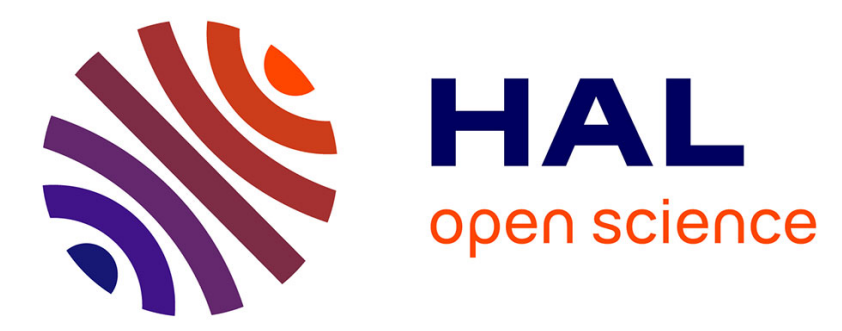

\title{
Excitation Transfer Process in Penning Ionization of the CO Molecule by Helium Atoms in Singlet Metastable State
}

B. Lescop, M. Ben Arfa, G. Le Coz, M. Cherid, G. Sinou, G. Fanjoux, A. Le Nadan, F. Tuffin

\section{To cite this version:}

B. Lescop, M. Ben Arfa, G. Le Coz, M. Cherid, G. Sinou, et al.. Excitation Transfer Process in Penning Ionization of the CO Molecule by Helium Atoms in Singlet Metastable State. Journal de Physique II, 1997, 7 (11), pp.1543-1554. 10.1051/jp2:1997202 . jpa-00248532

\section{HAL Id: jpa-00248532 https://hal.science/jpa-00248532}

Submitted on 1 Jan 1997

HAL is a multi-disciplinary open access archive for the deposit and dissemination of scientific research documents, whether they are published or not. The documents may come from teaching and research institutions in France or abroad, or from public or private research centers.
L'archive ouverte pluridisciplinaire HAL, est destinée au dépôt et à la diffusion de documents scientifiques de niveau recherche, publiés ou non, émanant des établissements d'enseignement et de recherche français ou étrangers, des laboratoires publics ou privés. 


\title{
Excitation Transfer Process in Penning Ionization of the CO Molecule by Helium Atoms in Singlet Metastable State
}

\author{
B. Lescop $\left(^{*}\right)$, M. Ben Arfa, G. Le Coz, M. Cherid, G. Sinou, G. Fanjoux, \\ A. Le Nadan and F. Tuffin \\ Laboratoire de Physique des Collisions Électroniques et Atomiques, \\ Faculté des Sciences et Techniques, Université de Bretagne Occidentale, \\ 6 avenue Le Gorgeu, B.P. 809, 29285 Brest Cedex, France
}

(Received 13 December 1996, revised 10 June 1997, accepted 16 July 1997)

PACS.34.50.Gb - Electronic excitation and ionization of molecules

\begin{abstract}
Penning ionization electron spectroscopy of the $\mathrm{CO}$ molecule by $\mathrm{He}^{*}\left(2^{1} \mathrm{~S}\right)$ metastable atoms is studied. Vibrational populations are reported for the three energetically accessible,states of the $\mathrm{CO}^{+}$ion $\left(\mathrm{X}^{2} \Sigma^{+}, \mathrm{A}^{2} \Pi\right.$ and $\left.\mathrm{B}^{2} \Sigma^{+}\right)$. An obvious discrepancy is observed between the excited vibrational levels of the $\mathrm{X}^{2} \Sigma^{+}$state and the calculated Franck-Condon factors. This result is attributed to an excitation transfer process via Rydberg vibrational progression converging to the $\mathrm{CO}^{+}\left(D^{2} \Pi\right)$ ionic state in agreement with the recent observations by fluorescence of neutral dissociate states. The presence of electrons coming from the well-known $\sigma$ shape resonance is not excluded.
\end{abstract}

\section{Introduction}

When a rare gas atom in a metastable state and an atomic or molecular target collide at thermal energies, Penning ionization may occur. To release this process, the excitation energy of the projectile must exceed the ionization potential of the target. Because of their high excitation energies, the $\mathrm{He}^{*}\left(2^{1,3} \mathrm{~S}\right)$ and $\mathrm{Ne}^{*}\left({ }^{3} \mathrm{P}_{0,2}\right)$ metastable atoms are the most widely used. Penning ionization may be described as follows:

$$
\mathrm{X}^{*}+\mathrm{AB} \longrightarrow \mathrm{X}+\mathrm{AB}^{+}+\mathrm{e}^{-}\left(E_{\mathrm{el}}\right)
$$

where $\mathrm{X}^{*}$ is an atom in a metastable state, $\mathrm{AB}$ is a molecular target, $\mathrm{AB}^{+}$is the residual ion in an electronic and vibrational state and $\mathrm{e}^{-}\left(E_{\mathrm{el}}\right)$ is the ejected electron with a kinetic energy $E_{\text {el }}$.

The most familiar path of Penning ionization is the ionization from the covalent channel, which is described by the $(\mathrm{X}-\mathrm{AB})^{*}$ quasi-bound state formed at short inter-particle separations. This state can autoionize because it is strongly coupled to the continuum of the $\mathrm{X}+\mathrm{AB}^{+}$ products plus a free electron. It has been shown theoretically and experimentally [1-3] that this ionization mechanism is generally an electron exchange process. Hence this short-range interaction consists, on the one hand, of a coupling between the $1 \mathrm{~s}^{-1}$ hole of $\mathrm{He}^{*}$ (or $2 \mathrm{p}^{-1}$ of $\mathrm{Ne}^{*}$ ) and a molecular orbital of the $\mathrm{AB}$ target and, on the other hand, of the coupling of the

(*) Author for correspondence: (e-mail: lescop@univ-brest.fr) 
2s electron of $\mathrm{He}^{*}$ (or $3 \mathrm{~s}$ of $\mathrm{Ne}^{*}$ ) with the continuum. So, in this mechanism, the ionization probability depends on the overlap of both target and projectile electronic clouds. However, a second process may contribute to the Penning ionization exclusively with the $\mathrm{He}^{*}\left(2^{1} \mathrm{~S}\right)$ as projectile. This is usually termed radiative or direct mechanism and it is described by a longrange dipole-dipole interaction between the projectile in a metastable state and the molecular target. This can be schematized by the absorption, by the target, of a virtual photon emitted by the metastable atom that de-excites to its ground state. By using a semi-classical approach, Djerad et al. [4] have shown that this radiative mechanism is the main process of ionization for systems involving excited alkali atoms $(\mathrm{Rb}, \mathrm{K})$ as colliding particles.

Penning electron energy spectra generally report similar electronic bands that are observed in photoionization. These bands present vibrational populations in rather good agreement with Franck-Condon factors [5] and they are usually broadened and shifted relatively to the nominal energy $E_{0}$ following the importance of the well depth of incoming and outcoming potential curves. The energy shift is defined as $\Delta E=E_{\mathrm{el}}-E_{0}$, where $E_{0}$ is given by the difference between the excitation energy of the projectile and the ionization potential of the target. This energy displacement $(\Delta E)$ corresponds to a change of both electronic energy and kinetic energy of heavy particles.

However, Penning ionization of some molecules may lead to non Franck-Condon vibrational populations [6-12]. These features are specific of collisions, in which the ionization process can arise via a secondary channel as described hereafter:

$$
\begin{aligned}
\mathrm{X}^{*}+\mathrm{AB} & \longrightarrow \mathrm{X}^{+}+\mathrm{AB}^{-} \longrightarrow \mathrm{X}+\mathrm{AB}^{+}+\mathrm{e}^{-} \\
& \longrightarrow \mathrm{X}+\mathrm{AB}^{* *} \longrightarrow \mathrm{X}+\mathrm{AB}^{+}+\mathrm{e}^{-}
\end{aligned}
$$

The first process (2a), non negligible for the molecular targets having a positive electron affinity like $\mathrm{SO}_{2}, \mathrm{NO}_{2}, \mathrm{O}_{2}, \mathrm{Cl}_{2}[6-9]$, arises by curve crossing, at intermediate inter-nuclear separations, between the incoming covalent channel and an intermediate ion pair state $\left(\mathrm{X}^{+}+\mathrm{AB}^{-}\right)$. The potential curve corresponding to this latter channel presents a strong attractive character, for which the well depth may reach several $\mathrm{eV}$. This process leads therefore to the production of low energy electrons. The second process (2b), in competition with the covalent channel, presents an excitation transfer between the reactants. This interaction lets the target in a Rydberg state which subsequently autoionizes. This process can occur resonantly, when the excitation energy of the incident metastable particles coincides with an autoionizing Rydberg state of the target like in $\mathrm{Ne}^{*}-\mathrm{CO}[10]$. Moreover, the excitation transfer may occur by curve crossing, at intermediate inter-nuclear separations, between the potential curve, which correlates asymptotically to $\mathrm{X}+\mathrm{AB}^{* *}$ products, and the incoming covalent channel like in $\mathrm{Ne}^{*}-\mathrm{CO}_{2}[11]$ or an intermediate ion pair state like in the $\mathrm{He}^{*}-\mathrm{Cl}_{2}$ system [12].

The electron spectrum features (energy displacement, symmetry of the peaks, relative vibrational populations and angular distribution of the ejected electrons) are useful to characterize an indirect process, u.e. excitation transfer or ion pair state, added to the covalent channel [13].

Penning ionization of the CO molecule has been widely studied by electronic $[2,11,14-19]$ and optical spectroscopies [20] with helium atoms in metastable triplet state. The reported vibrational populations were in agreement with the Franck-Condon factors; consequently the high domination of the covalent channel was expected. However, Lescop et al. [21] have recently emphasized the existence of an added ionization mechanism in the $\mathrm{He}\left(2^{3} \mathrm{~S}\right)-\mathrm{CO}$ collision by reporting a non Franck-Condon vibrational population of the $\mathrm{X}^{2} \Sigma^{+}$state of $\mathrm{CO}^{+}$Similar features have been also observed by Wannberg et al. [22] with HeI excitation photons. So, to explain these experimental results, both ionization processes have been assumed to occur via an intermediate autoionizing Rydberg state. We must indicate that, in the 19-25 eV energy 
range, many autoionizing states of neutral CO have been evidenced by photoabsorption [23-26] and by electron impact spectroscopy [27]. These states have been attributed to Rydberg states converging to the $\mathrm{B}^{2} \Sigma^{+}$state of $\mathrm{CO}^{+}[23]$ as well as double-electron excitation states [24-27]. Recently, Rydberg progressions converging to the $\mathrm{B}^{2} \Sigma^{+}, \mathrm{C}^{2} \Sigma^{+}, \mathrm{D}^{2} \Pi$ and $E^{2} \Pi$ ionic states have been reported from $19 \mathrm{eV}$ to $22 \mathrm{eV}[28,29]$. Energies of some Rydberg states converging to $\mathrm{C}^{2} \Sigma^{+}$and $D^{2} \Pi$ are in the vicinity of excitation energy of $\mathrm{He}^{*}\left(2^{1} \mathrm{~S}: 20.616 \mathrm{eV}\right)$ atoms. Consequently, investigating the $\mathrm{He}^{*}\left(2^{1} \mathrm{~S}\right)-\mathrm{CO}$ interaction is important to underline the importance of an eventual excitation transfer. Moreover, these autoionizing states overlap with a broad $\sigma$ shape resonance $[30,31]$.

High resolution experimental Penning ionization electron spectroscopy of CO with singlet helium metastable state was carried out in our laboratory for the three accessible electronic levels to probe the dynamics of this collision system. Vibrational populations were measured for all the electronic levels $\left(\mathrm{X}^{2} \Sigma^{+}, \mathrm{A}^{2} \Pi\right.$ and $\left.\mathrm{B}^{2} \Sigma^{+}\right)$. Section 2 of this paper gives a short description of the experimental apparatus. The results of measurements are reported in Section 3 and the existing processes leading to the ionization of $\mathrm{CO}^{+}$are discussed. Our conclusions are summarized in the last section.

\section{Experiment}

The apparatus was described in detail in previous papers [32,33]. Metastable states were obtained by transverse electron impact produced by a heated tungsten filament operating at a negative potential $(-30 \mathrm{~V}$ to $-90 \mathrm{~V}$ with respect to the collision box) and at fixed total emission current $I_{\mathrm{f}}=0.3 \mathrm{~mA}$. The metastable flux (singlet and triplet), measured by secondary electron emission, was around $10^{10}$ atoms $\mathrm{s}^{-1}$. The flux ratio of the metastable states $\mathrm{He}^{*}\left(2^{1} \mathrm{~S}\right) / \mathrm{He}^{*}\left(2^{3} \mathrm{~S}\right)$ depended on the electron energy and was monitored via Penning ionization electron spectroscopy of Ar. At $30 \mathrm{eV}$ and $90 \mathrm{eV}$, the lowest and highest electron energies studied, the flux ratio of metastable components was in the range of 0.86-3.78 in agreement with the observations of Dugan et al. [34]. Experimental spectra were obtained with the extreme incident electron energy conditions to minimize one component. After subtractions, the separated spectra with the two electronic states of helium metastable were extracted, but, this technique was possible only when the observed structures were not too weak. Because this operation can generate important oscillation features in the electron energy spectrum due to the statistical noise. Oscillations, thus, make the observation of the weak structures problematic.

The metastable projectile and the target beams were formed by effusion through a multicapillary array and crossed at right angles. The mean velocity of the $\mathrm{He}^{*}$ projectile corresponded to an effective temperature of $500 \mathrm{~K}$, whereas the effective temperature of the target was $300 \mathrm{~K}$. These experimental conditions led to a relative collision kinetic energy of $E_{\text {coll }}=60 \mathrm{meV}$. Electrons, which were ejected from the collision region, were analysed in angle and in energy with a $127^{\circ}$ cylindrical analyser, rotating around the target beam axis, with a resolution of $45 \mathrm{meV}$. This was determined from the photoelectron spectrum of $\mathrm{Ar}^{+}$with $584 \AA$ photons, which were produced in our metastable source. At the $3 \mathrm{eV}$ pass energy used in our experiment, the spectrometer transmission function was controlled. The comparison of our spectra with those obtained by Ohno et al. [17] for the $\mathrm{He}^{*}\left(2^{3} \mathrm{~S}\right)-\mathrm{N}_{2}, \mathrm{C}_{2} \mathrm{H}_{2}$ systems shows that this function decreases by $25 \%$ between 8 and $0.3 \mathrm{eV}$. However, this variation can be neglected with respect to the vibrational levels belonging to the same electronic band. The geomagnetic field was reduced to about $10 \mathrm{mG}$ with the use of Helmholtz coils surrounding the electron spectrometer. The background pressure measured with an ion gauge was about $1 \times 10^{-7}$ torr. When the metastable beam was in use, the pressure increased to $1 \times 10^{-5}$ torr and the total 


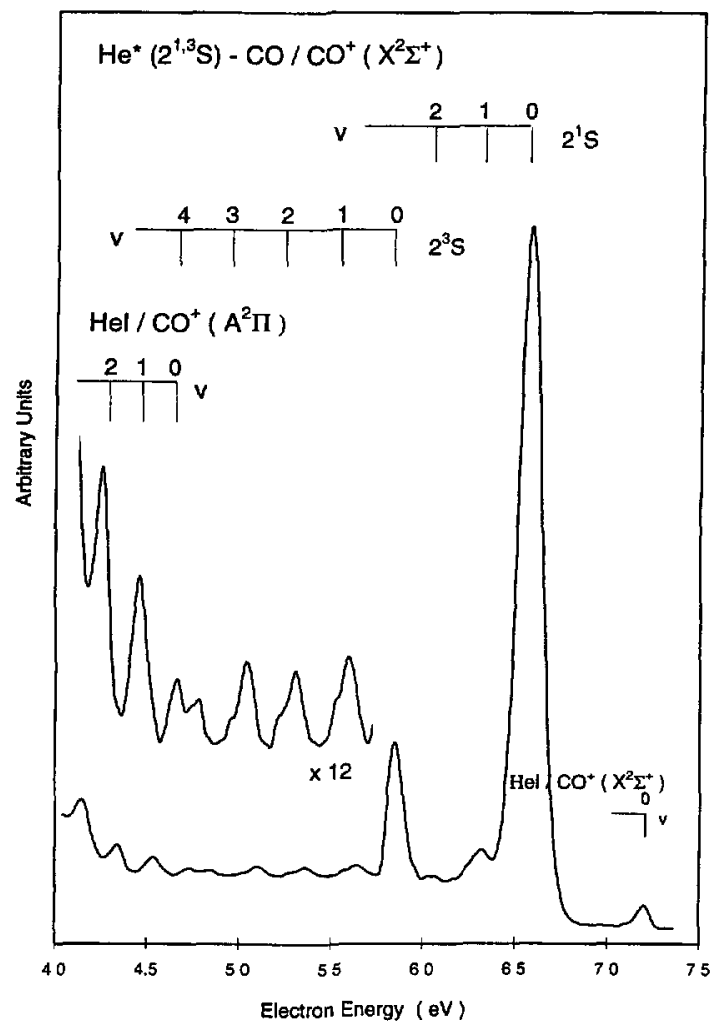

Fig. 1. - Electron energy spectrum for $\mathrm{He}^{*}-\mathrm{CO} / \mathrm{CO}^{+}\left(\mathrm{X}^{2} \Sigma^{+}\right)$Penning ionization observed at $40^{\circ}$ detection angle with a filament voltage fixed at $90 \mathrm{~V}$ (see text).

pressure (He and $\mathrm{CO}$ ) was kept constant at $3 \times 10^{-5}$ torr.

\section{Results and Discussion}

The configuration of the fundamental state of CO is $(1 \sigma)^{2}(2 \sigma)^{2}(3 \sigma)^{2}(4 \sigma)^{2}(1 \pi)^{4}(5 \sigma)^{2}$. The removal of an electron from the $5 \sigma, 1 \pi$ or $4 \sigma$ orbital leads to the three first electronic states of the $\mathrm{CO}^{+}$ion $\left(\mathrm{X}^{2} \Sigma^{+}, \mathrm{A}^{2} \Pi\right.$ and $\left.\mathrm{B}^{2} \Sigma^{+}\right)$. These states are energetically accessible by Penning ionization with helium atoms in metastable state. Each electronic state of $\mathrm{CO}^{+}$is investigated to study the dynamics of the ionizing process in the $\mathrm{He}^{*}\left(2^{1,3} \mathrm{~S}\right)-\mathrm{CO}$ collisions.

3.1. The $\mathrm{X}^{2} \Sigma^{+}$STATE. - Figure 1 presents the energy spectrum of ejected electrons in Penning ionization by helium atoms in the $\mathrm{He}^{*}\left(2^{1,3} \mathrm{~S}\right)$ metastable states. This spectrum reports the structures corresponding to the ground electronic state of $\mathrm{CO}^{+}$measured at $\theta_{\mathrm{Lab}}=40^{\circ}$. The filament voltage was fixed at $90 \mathrm{~V}$ to minimize the density of the $\mathrm{He}^{*}\left(2^{3} \mathrm{~S}\right)$ atoms in the incident beam, and consequently, to increase the current of the electrons coming from the $\mathrm{He}^{*}\left(2^{1} \mathrm{~S}\right)-\mathrm{CO}$ collision. The structures corresponding to the photoionization of $\mathrm{CO}$ with $\mathrm{HeI}$ radiation were used to calibrate the spectrum in energy (see Fig. 1). This spectrum clearly shows two intense peaks corresponding to the ground vibrational state of $\mathrm{CO}^{+}$coming from the $\mathrm{He}^{*}\left(2^{1} \mathrm{~S}\right)-\mathrm{CO}$ and $\mathrm{He}^{*}\left(2^{3} \mathrm{~S}\right)-\mathrm{CO}$ interactions. The measured en- 
Table I. - Energy shifts (in $\mathrm{meV}$ ) of the electronic states of $\mathrm{CO}^{+}$

\begin{tabular}{|c|c|c|c|c|c|c|}
\hline & \multicolumn{2}{|c|}{$\mathrm{X}^{2} \Sigma^{+}$} & \multicolumn{2}{|c|}{$\mathrm{A}^{2} \Pi$} & \multicolumn{2}{|c|}{$\mathrm{B}^{2} \Sigma^{+}$} \\
\hline & $\mathrm{He}^{*}\left(2^{1} \mathrm{~S}\right)$ & $\mathrm{He}^{*}\left(2^{3} \mathrm{~S}\right)$ & $\mathrm{He}^{*}\left(2^{1} \mathrm{~S}\right)$ & $\mathrm{He}^{*}\left(2^{3} \mathrm{~S}\right)$ & $\mathrm{He}^{*}\left(2^{1} \mathrm{~S}\right)$ & $\mathrm{He}^{*}\left(2^{3} \mathrm{~S}\right)$ \\
\hline Our results & $-20 \pm 5$ & $+45 \pm 5$ & $+30 \pm 7$ & $+40 \pm 7$ & $-20 \pm 5$ & \\
\hline Cermak [11] & -30 & +25 & & & +15 & \\
\hline Hotop and Niehaus [14] & $-20 \pm 10$ & $+45 \pm 10$ & & $+35 \pm 15$ & +40 & \\
\hline Yee et al. [15] & $-14 \pm 10$ & $+43 \pm 10$ & & $+47 \pm 10$ & $+49 \pm 10$ & \\
\hline
\end{tabular}

ergy displacements of these structures presented in Table I are in excellent agreement with previous works $[11,15,16]$. These results $\left(\Delta E_{1}<0\right.$ and $\left.\Delta E_{3}>0\right)$ therefore show the more attractive character of the incoming potential curve of the $\mathrm{He}^{*}\left(2^{1} \mathrm{~S}\right)-\mathrm{CO}$ interaction compared to $\mathrm{He}^{*}\left(2^{3} \mathrm{~S}\right)-\mathrm{CO}$. Moreover, the well depths of these interactions can be estimated by measuring the $D^{*}=E_{0}-E_{44}+V^{+}\left(R^{*}\right)$ quantity [35], where $E_{0}$ is the nominal energy position (defined in the introduction) and $E_{44}$ is the low energy edge that corresponds to the energy position for which the peak intensity reaches $44 \%$ of its maximum on the low energy side. Moreover $V^{+}\left(R^{*}\right)$ is the depth of the outgoing potential curve at the inter-particle distance corresponding to the edge. In accordance with the recent studies of Yencha et al. [36,37], this value was estimated to be $20 \mathrm{meV}$. The well depths of $\mathrm{He}^{*}\left(2^{1} \mathrm{~S}\right)-\mathrm{CO}$ and $\mathrm{He}^{*}\left(2^{3} \mathrm{~S}\right)-\mathrm{CO}$ interactions were found at $D_{1}^{*}=130 \mathrm{meV}$ and $D_{3}^{*}=35 \mathrm{meV}$ respectively. The more attractive behaviour of the interaction with singlet atoms in the case of $\mathrm{He}^{*}-\mathrm{H}_{2} \mathrm{O}, \mathrm{Mg}, \mathrm{Ca}[33,38]$ was related to the different polarisability of the metastable atoms which are $\alpha_{1}=788 a_{0}^{3}$ and $\alpha_{3}=313 a_{0}^{3}$ respectively for $\mathrm{He}^{*}\left(2^{1} \mathrm{~S}\right)$ and $\mathrm{He}^{*}\left(2^{3} \mathrm{~S}\right)$.

The vibrational levels of $\mathrm{CO}^{+}\left(\mathrm{X}^{2} \Sigma^{+}\right)$produced in the $\mathrm{He}^{*}\left(2^{3} \mathrm{~S}\right)-\mathrm{CO}$ interaction are reported up to $v=4$ in the spectrum of Figure 1. Higher vibrational states $(v \geq 5)$ are not observed because of the superimposed presence of low contribution of HeI photoelectrons spectrum resulting from the formation of $\mathrm{CO}^{+}\left(\mathrm{A}^{2} \Pi\right)$ in the first vibrational levels. The observation of the vibrational structures is allowed by the strong signal to noise ratio existing in our experiment. A shoulder can be seen on the low energy side of the $v=1-4$ vibrational states. This feature is not observed in the spectrum of Figure 2. It is masked by the important weight of the peaks due to the $\mathrm{He}^{*}\left(2^{3} \mathrm{~S}\right)$ atoms. This difference results from a change in electron energy in the metastable chamber. Consequently, the $I_{3} / I_{1}$ intensity flux ratio of metastable components rises from 0.3 in Figure 1 spectrum to 1.1 in Figure 2 spectrum. According to the expected energy positions of both vibrational progressions associated to the ionization by singlet and triplet metastable helium atoms, the asymmetry reported in Figure 1 can therefore be assigned to the $v=4-7$ levels of the $\mathrm{CO}^{+}\left(\mathrm{X}^{2} \Sigma^{+}\right)$ion associated to the $\mathrm{He}^{*}\left(2^{1} \mathrm{~S}\right)-\mathrm{CO}$ interaction. To extract more information about the vibrational levels of both series, the spectrum in Figure 1 was decomposed.

Figure 3 shows a part of an experimental spectrum, with a strong contribution of electrons released from the $\mathrm{He}^{*}\left(2^{1} \mathrm{~S}\right)-\mathrm{CO}$ interaction in a limited electron energy range from $4.6 \mathrm{eV}$ to $5.7 \mathrm{eV}$. After subtracting an adequate background function, this spectrum was decomposed into two vibrational series produced by $\mathrm{He}^{*}\left(2^{1} \mathrm{~S}\right)$ and $\mathrm{He}^{*}\left(2^{3} \mathrm{~S}\right)$ atoms. The intensity of vibrational peaks was optimized while taking into account their energy spacings given by the spectroscopic data [22], and a line shape, which was derived according to the one of the intense ground vibrational level. Table II presents calculated Franck-Condon factors [39], and the populations, given by the area of decomposed vibrational peaks. The values of the high vibrational levels population are more qualitative than quantitative because of uncertainties due 


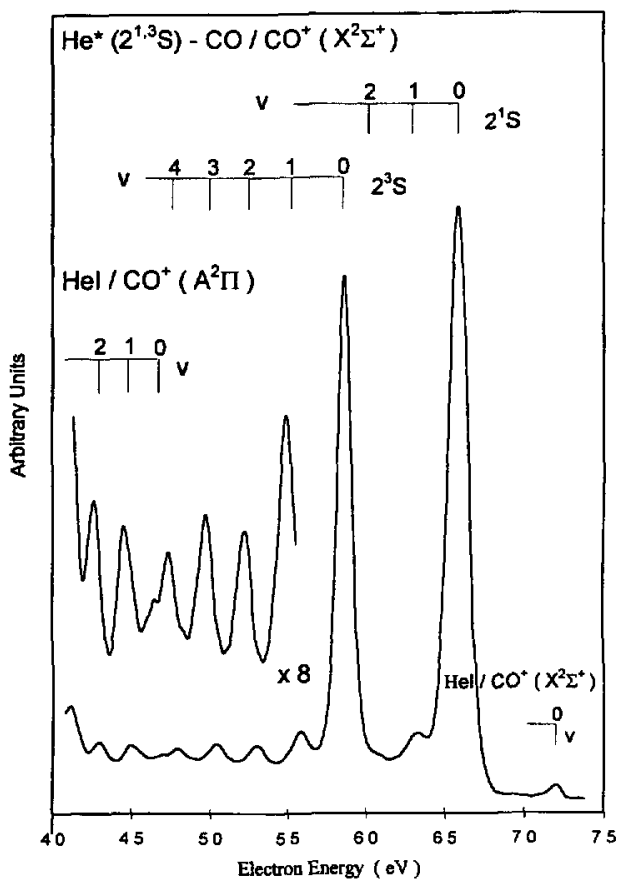

Fig. 2. - Electron energy spectrum for the collision system $\mathrm{He}^{*}-\mathrm{CO} / \mathrm{CO}^{+}\left(\mathrm{X}^{2} \Sigma^{+}\right)$observed at $40^{\circ}$ detection angle with a filament voltage fixed at $35 \mathrm{~V}$ (see text).

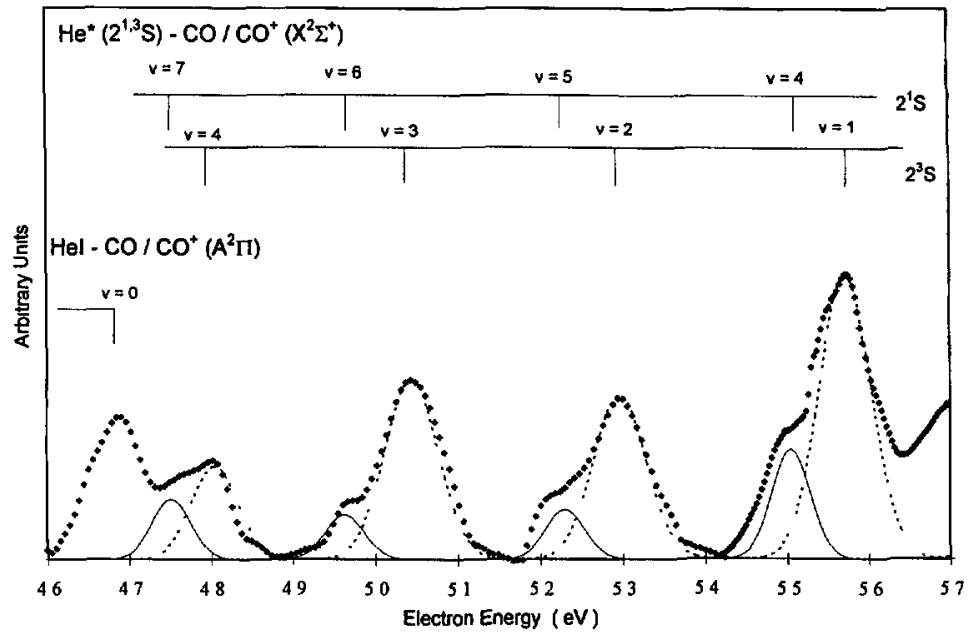

Fig. 3. - Diamonds represent experimental electron energy spectrum for the collision system $\mathrm{He}^{*}-\mathrm{CO} / \mathrm{CO}^{+}\left(\mathrm{X}^{2} \Sigma^{+}\right)$between 4.2 and $5.7 \mathrm{eV}$ observed at $40^{\circ}$ detection angle with a filament voltage fixed at $90 \mathrm{~V}$. This spectrum is decomposed into two spectra obtained with $\mathrm{He}^{*}\left(2^{1} \mathrm{~S}\right)$ and $\mathrm{He}^{*}\left(2^{3} \mathrm{~S}\right)$ atoms respectively in full and dotted lines. 
Table II. - Populations are normalized relatively to the $v=0$ ground vibrational state. Photoelectron spectrum of Wannberg et al. [22] were scanned and fitted to present these results.

\begin{tabular}{|c|c|c|c|c|c|c|c|c|}
\hline & $v=0$ & $v=1$ & $v=2$ & $v=3$ & $v=4$ & $v=5$ & $v=6$ & $v=7$ \\
\hline $\begin{array}{l}\text { Franck-Condon factors } \\
\text { Nicholls [39] }\end{array}$ & 100 & 3.6 & 0.01 & $<10^{-3}$ & & & & \\
\hline $\begin{array}{l}\text { Photozonization by } 584 \AA \\
\text { Wannberg et al. [22] }\left(^{*}\right)\end{array}$ & 100 & 5.2 & 1.1 & 15 & 08 & 0.5 & 0.7 & 0.8 \\
\hline $\begin{array}{l}\text { Penning ionzzation by } \mathrm{He}^{*}\left(2^{1} \mathrm{~S}\right) \\
\text { Our results } \\
\text { Hotop and Niehaus [14] }\end{array}$ & $\begin{array}{l}100 \\
100 \\
\end{array}$ & $\begin{array}{c}4.5 \pm 05 \\
4 \pm 2 \\
\end{array}$ & $0.9 \pm 0.3$ & $\ldots$ & $0.4 \pm 0.2$ & $0.2 \pm 0.1$ & $01 \pm 0.1$ & $02=01$ \\
\hline $\begin{array}{l}\text { Penning onzzation by } \mathrm{He}^{*}\left(2^{3} \mathrm{~S}\right) \\
\text { Our results } \\
\text { Hotop and Niehaus }[14] \\
\text { Yee et al. }[15]\end{array}$ & $\begin{array}{l}100 \\
100 \\
100\end{array}$ & $\begin{aligned} 7.4 & \pm 0.5 \\
5 & \pm 2 \\
8 & \pm 1\end{aligned}$ & $\begin{array}{l}2.4 \pm 0.4 \\
2 \pm 1\end{array}$ & $22 \pm 0.4$ & $1.8 \pm 0.4$ & & & \\
\hline
\end{tabular}

(*) The data of Wannberg et al. had been graphically extracted from Figure 3 of reference [22]

to the fitting procedure. The population of the $v=3$ level produced by the $\operatorname{He}^{*}\left(2^{1} \mathrm{~S}\right)$ atoms is not reported because it overlaps the vibrational ground state $(v=0)$ due to $\mathrm{He}^{*}\left(2^{3} \mathrm{~S}\right)$. Table II shows an obvious discrepancy between the calculated Franck-Condon factors and the reported populations. A weak difference could be related to a deformation of the molecule when the metastable atoms approach as observed in the case of the $\mathrm{He}^{*}\left(2^{3} \mathrm{~S}\right)-\mathrm{HCl}[40]$. But the drastic difference observed in the present study reveals the existence of an indirect process which competes with the covalent channel. The weakness of the energy displacement of the structures allows to exclude the existence of an ion-pair channel in the collision. Thus, only the Van der Waals interaction plays a role in the $\mathrm{He}^{*}-\mathrm{CO}$ interaction and so the secondary process must be an excitation transfer between the colliding particles. However, Siska [19] recently studied the $\mathrm{He}^{*}\left(2^{1} \mathrm{~S}\right)$ - $\mathrm{CO}$ interaction by subtracting from a mixed $\mathrm{He}^{*}\left(2^{1,3} \mathrm{~S}\right)-\mathrm{CO}$ spectrum a pure $\mathrm{He}^{*}\left(2^{3} \mathrm{~S}\right)$ - $\mathrm{CO}$ spectrum obtained thanks to a quenching lamp. He reported a weak continuum, that he attributed to overlapping Rydberg states. It should be noted that Siska [19] did not either observed the high vibrational levels of $\mathrm{CO}^{+}\left(\mathrm{X}^{2} \Sigma^{+}\right)$produced in the $\mathrm{He}^{*}\left(2^{3} \mathrm{~S}\right)$ - CO interaction [21]. The difference between our results and Siska's one must be due to the signal to noise ratio, which is around 100:2 in our spectrum making possible the observation of weak structures [21].

The non Franck-Condon behaviour of the $\mathrm{X}^{2} \Sigma^{+}$state of $\mathrm{CO}^{+}$reported with $\mathrm{He}^{*}\left(2^{3} \mathrm{~S}\right)$ atoms [21] was attributed to an excitation transfer to intermediate Rydberg states converging to the $\mathrm{D}^{2} \Pi$ state of $\mathrm{CO}^{+}[28,29]$. According to electronic Rydberg state configuration calculated by Lavendy et al. [41], autoionization states can decay to both $\mathrm{X}^{2} \Sigma^{+}$and $\mathrm{B}^{2} \Sigma^{+}$ states $[21,22]$. Concerning the $\mathrm{He}^{*}\left(2^{1} \mathrm{~S}\right)-\mathrm{CO}$ interaction, Rydberg states converging to $\mathrm{C}^{2} \Sigma^{+}$ $\left(3 \mathrm{p}_{v=1}, 3 \mathrm{~s}_{v=9} \cdot 20.67 \mathrm{eV}\right)$ or to $\mathrm{D}^{2} \Pi\left(3 \mathrm{~s}_{v=8} \cdot 20.66 \mathrm{eV}\right)$ have been found to have an energy close to the excitation energy of $\mathrm{He}^{*}\left(2^{1} \mathrm{~S}\right)$ atoms [29]. In the Franck-Condon region of the $v=0$ level of $\mathrm{CO}\left(\mathrm{X}^{1} \Sigma^{+}\right)$, the electronic configuration of Rydberg states converging to $\mathrm{C}^{2} \Sigma^{+}$is $\mathrm{K} \mathrm{K}$ $(1 \pi)^{-1}(5 \sigma)^{-1}(2 \pi)^{1}$ (3s or $\left.3 p\right)^{1}[41-45]$. Consequently, autoionization of these Rydberg states can be caused by the transition of the $2 \pi$ electron to the $5 \sigma$ or $1 \pi$ orbital and by the simultaneous ejection of the outer $3 \mathrm{~s}$ (or $3 \mathrm{p}$ ) electron. This feature leads to a non Franck-Condon vibrational behaviour of both $\mathrm{A}^{2} \Pi$ and $\mathrm{X}^{2} \Sigma^{+}$states respectively. Autoionization of Rydberg states converging to $\mathrm{C}^{2} \Sigma^{+}$or $\mathrm{D}^{2} \Pi$ states therefore lead to non Franck-Condon behaviour of the $\mathrm{X}^{2} \Sigma^{+}$state. The $\mathrm{CO}^{+}\left(\mathrm{A}^{2} \Pi\right)$ state produced by $\mathrm{He}^{*}\left(2^{1} \mathrm{~S}\right)$ atoms must be investigated to report information on the vibrational levels and so to show the Rydberg states converging to $\mathrm{CO}^{+}\left(\mathrm{C}^{2} \Sigma^{+}\right.$or $\left.\mathrm{D}^{2} \Pi\right)$ states involved in this interaction. 

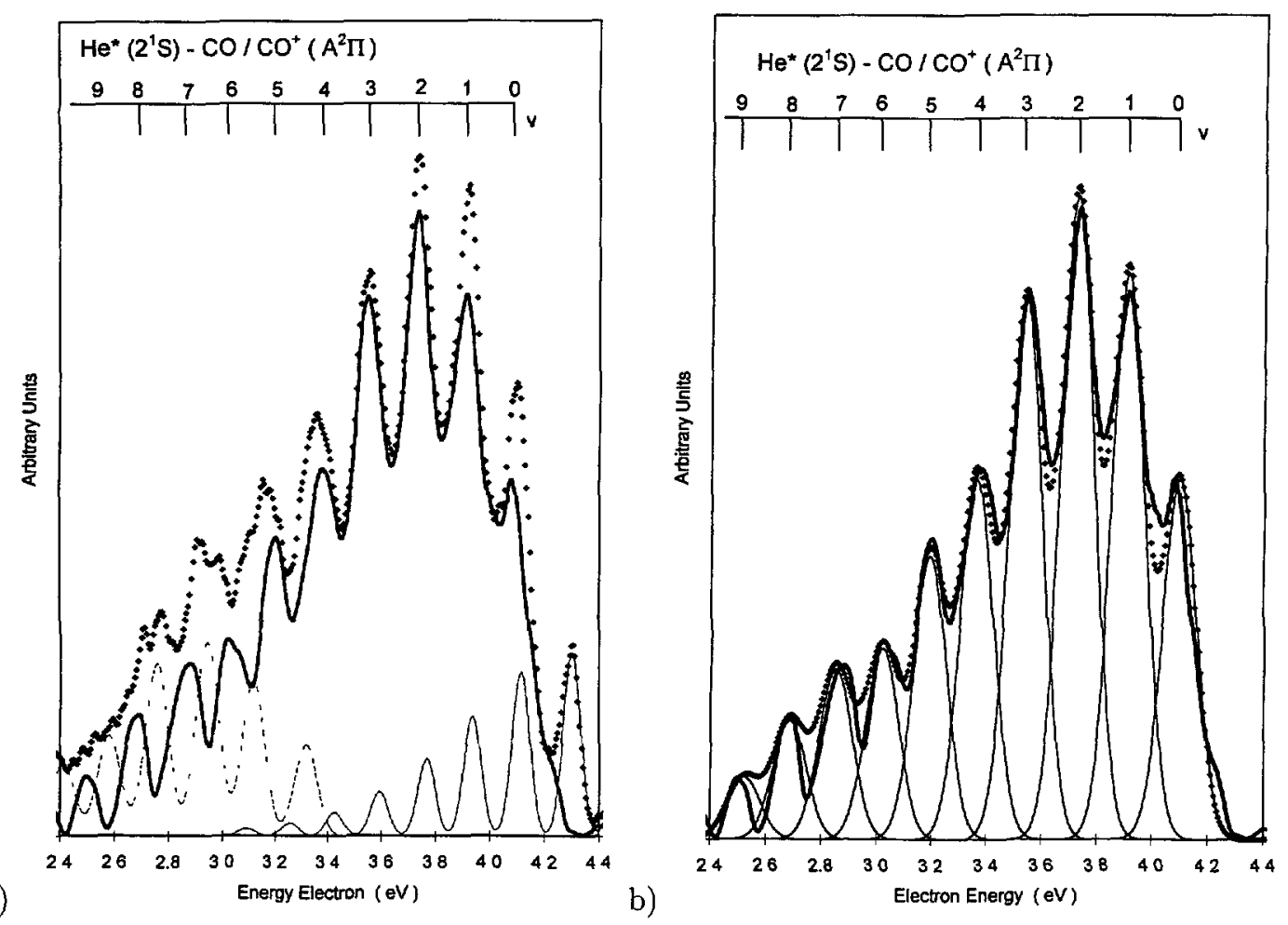

Fig. 4. - a) Bold line represents electron energy spectrum for $\mathrm{He}^{*}\left(2^{1} \mathrm{~S}\right)-\mathrm{CO}$ containing the $\mathrm{CO}^{+}\left(\mathrm{A}^{2} \Pi\right)$ state obtained by subtraction of a synthesized triplet spectrum (dashed line) from a mixed one (diamonds). Photoelectron spectrum for $584 \AA-\mathrm{CO} / \mathrm{CO}^{+}\left(\mathrm{A}^{2} \Pi\right)$ is also subtracted (thin line). b) Thin lines represent the decomposed vibrational peaks of the electron energy spectrum for $\mathrm{He}^{*}\left(2^{1} \mathrm{~S}\right)-\mathrm{CO} / \mathrm{CO}^{+}\left(\mathrm{A}^{2} \Pi\right)$. The sum of these structures is also shown (diamonds).

3.2. The $A^{2} \Pi$ STATE. - Figure $4 \mathrm{a}$ presents electron energy spectrum of the first excited electronic state $\mathrm{A}^{2} \Pi$ of the $\mathrm{CO}^{+}$ion produced by $\mathrm{He}^{*}\left(2^{1} \mathrm{~S}\right)-\mathrm{CO}$ interaction. This spectrum was obtained by subtracting from a mixed spectrum a synthesized pure triplet spectrum, which was built from energy shift, vibrational populations and widths given by the previous measurements $[11,14,15]$. Moreover, the photoelectrons corresponding to the $A^{2} \Pi$ state produced by $584 \AA$ photons were subtracted too. The energy displacement, given in Table $\mathrm{I}$, is obviously different from the observed shift of $\mathrm{X}^{2} \Sigma^{+}$state, indicating the different characters of incoming potential curves that lead to the $\mathrm{X}^{2} \Sigma^{+}$and $\mathrm{A}^{2} \Pi$ states, because a positive energy shift can be associated to a repulsive, or less attractive, incoming potential. Figure $4 \mathrm{~b}$ presents the decomposition of spectrum into vibrational structures. This procedure allows us to measure the $E_{44}$ quantity, which is equal to $45 \pm 5 \mathrm{meV}$. Following the arguments presented in the previous part of the paper, the well depth of the entrance channel leading to $A^{2} \Pi$ state is estimated at $65 \mathrm{meV}$. Ionization into the $\mathrm{X}^{2} \Sigma^{+}$state corresponds to the removal of $\sigma$ electron localised on the $\mathrm{C}$ atom. while formation of $\mathrm{A}^{2} \Pi$ requires the removal of $\pi$ electron localised between these atoms. For the latter, $\mathrm{He}^{*}$ attack perpendicularly to the molecular axis is more effective, whereas for $\mathrm{X}^{2} \Sigma^{+}$state, $\mathrm{He}^{*}$ approach along the molecular axis is favourable on the carbon atom side. Therefore, the estimated well depths difference reflects the anisotropy of the 
Table III. - Populations are normalised relatively to the $v=2$ vibrational state. Photoelectron spectrum of Wannberg et al. [22] were scanned and fitted to present these results.

\begin{tabular}{|l|ccccccccc|}
\hline & $v=0$ & $v=1$ & $v=2$ & $v=3$ & $v=4$ & $v=5$ & $v=6$ & $v=7$ & $v=8$ \\
\hline $\begin{array}{l}\text { Franck-Condon factors } \\
\text { Nicholls [39] }\end{array}$ & 37 & 82 & 100 & 89 & 65 & 42 & 24 & 13 & 7 \\
$\begin{array}{l}\text { Photoronization by } 584 \AA \\
\begin{array}{l}\text { Wannberg et al. }[22] \\
\text { Pennıng zonization by } \\
\text { Our results }\end{array}\end{array} \mathrm{He}^{*}\left(2^{1} \mathrm{~S}\right)$ & 43 & 83 & 100 & 83 & 64 & 55 & 23 & 17 & 8 \\
\hline
\end{tabular}

entrance channel potential surface and so shows that $\mathrm{He}^{*}\left(2^{1} \mathrm{~S}\right)-\mathrm{CO}$ interaction is less attractive when $\mathrm{He}^{*}$ approaches perpendicularly to the molecular axis.

Vibrational populations of the $\mathrm{A}^{2} \Pi$ state up to $v=7$ are given in Table III. This table also contains the Franck-Condon factors [39] calculated for a vertical transition from $\mathrm{CO}\left(\mathrm{X}^{1} \Sigma^{+}\right)$ to $\mathrm{CO}^{+}\left(\mathrm{A}^{2} \Pi\right)$ and photoionization populations [22]. A good agreement is observed between the calculated factors and the vibrational populations obtained by Penning ionization as well as photoionization. However, a weak discrepancy due to the subtraction is observed for the $v \geq 6$ vibrational levels. The populations show the dominant character of covalent channel process that populates the $\mathrm{A}^{2} \Pi$ state in the $\mathrm{He}^{*}\left(2^{1} \mathrm{~S}\right)-\mathrm{CO}$ interaction.

3.3. The $\mathrm{B}^{2} \Sigma^{+}$STATE. - Figure 5 presents a spectrum of the $\mathrm{B}^{2} \Sigma^{+}$state produced by $\mathrm{He}^{*}\left(2^{1} \mathrm{~S}\right)$. The excitation energy of $\mathrm{He}^{*}\left(2^{1} \mathrm{~S}\right)$ is sufficient to produce this ionic state up to $v=3$ vibrational levels. The energy shift of the $v=0$ level is presented in Table I. However, this value is not in agreement with the displacements observed previously by Hotop and Niehaus [14] and by Yee et al. [15]. We attribute this discrepancy to the background that existed in the previous experimental spectra which was higher than the one observed in our experiment. The well depth leading to populate the $\mathrm{B}^{2} \Sigma^{+}$state is estimated at $125 \pm 5 \mathrm{meV}$. This measurement is in agreement with the one reported for $\mathrm{X}^{2} \Sigma^{+}$within the respective experimental uncertainties. This feature is consistent with the fact that ionization into both $\mathrm{X}^{2} \Sigma^{+}$and $\mathrm{B}^{2} \Sigma^{+}$states corresponds to the removal of $\sigma$ electron and so to a collision geometry configuration where $\mathrm{He}^{*}$ approaches along the inter-nuclear axis.

The vibrational populations corresponding to the $\mathrm{He}^{*}\left(2^{1} \mathrm{~S}\right)-\mathrm{CO}$ interaction are reported in Table IV. By photoionization, Wannberg et al. [22] have exhibited a non Franck-Condon behaviour of high vibrational levels consistent with an indirect process. In the case of Penning ionization with $\mathrm{He}^{*}\left(2^{1} \mathrm{~S}\right)$ atoms, excitation energy is not sufficient to populate high vibrational levels. So the present results cannot be compared to photoionization result. However, an agreement between our results and the Franck-Condon factors [39] is observed. This feature can be explained by the fact that the first vibrational levels are mainly populated via the covalent channel.

\section{Summary}

The experimental spectra reported in the present work show the high domination of covalent channel concerning first vibrational levels in the $\mathrm{He}^{*}\left(2^{1} \mathrm{~S}\right)-\mathrm{CO}$ interaction. However, additional vibrational structures of the $\mathrm{CO}^{+}\left(\mathrm{X}^{2} \Sigma^{+}\right)$state produced by $\mathrm{He}^{*}\left(2^{1} \mathrm{~S}\right)$ were observed; they reveal the existence of an indirect process. Vibrational observed population 


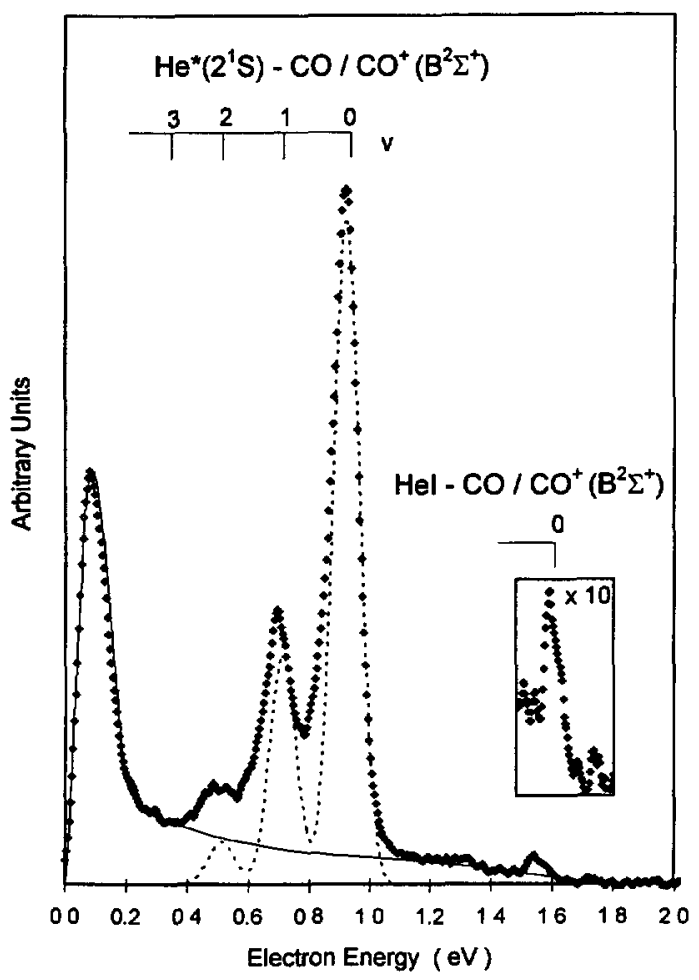

Fig. 5. - Diamonds represent electron energy spectrum for $\mathrm{He}^{*}\left(2^{1} \mathrm{~S}\right)-\mathrm{CO} / \mathrm{CO}^{+}\left(\mathrm{B}^{2} \Sigma^{+}\right)$Penning ionization observed at $40^{\circ}$ detection angle with a filament voltage fixed at $90 \mathrm{~V}$. The decomposed vibrational peaks and the background are indicated respectively by a dashed and a thin line.

Table IV. - Populations are normalised relatively to the $v=0$ ground vibrational state. Photoelectron spectrum of Wannberg et al. [22] were scanned and fitted to present these results.

\begin{tabular}{|l|cccc|}
\hline & $v=0$ & $v=1$ & $v=2$ & $v=3$ \\
\hline Franck - Condon factors & & & & \\
Nicholls [39] & 100 & 36 & 7 & 1 \\
Photoionzzation by $584 \AA$ & & & & \\
Wannberg et al. $[22]$ & 100 & 50 & 14 & 5 \\
Penning ionzzation by $\mathrm{He}^{*}\left(2^{1} \mathrm{~S}\right)$ & & & & \\
Our results & 100 & $32 \pm 3$ & $5 \pm 2$ & \\
Hotop and Niehaus [14] & 100 & $38 \pm 4$ & $5 \pm 2$ & \\
Yee et al. $[15]$ & 100 & $28 \pm 14$ & & \\
\hline
\end{tabular}

of $\mathrm{X}^{2} \Sigma^{+}$state is consistent with the hypothesis of ionization via intermediate Rydberg states converging to $\mathrm{C}^{2} \Sigma^{+}$or $\mathrm{D}^{2} \Pi$ two-electron excitation states. However, Rydberg states converging to $\mathrm{CO}^{+}\left(\mathrm{D}^{2} \Pi\right)$ state decay to both $\mathrm{X}^{2} \Sigma^{+}$and $\mathrm{B}^{2} \Sigma^{+}$states, whereas those converging to $\mathrm{CO}^{+}\left(\mathrm{C}^{2} \Sigma^{+}\right)$state populate both $\mathrm{X}^{2} \Sigma^{+}$and $\mathrm{A}^{2} \Pi$ states. Following the reported FranckCondon behaviour of $\mathrm{A}^{2} \Pi$ state, an excitation transfer process via a Rydberg state converging 
to $D^{2} \Pi$ state is effective in the $\mathrm{He}^{*}\left(2^{1} \mathrm{~S}\right)-\mathrm{CO}$ interaction. The recent observations of $\mathrm{D}^{2} \Pi$ Rydberg states resonant in energy with singlet metastable atoms $[28,29]$ are consistent with our conclusion. In addition, it is not excluded that the well know broad $\sigma$ shape resonance observed in photoionization around $24 \mathrm{eV}[30,31]$ can take place in the $\mathrm{He}^{*}-\mathrm{CO}$ collision to cause deviation of the vibrational population from the predicted Franck-Condon factors. The role of shape resonance in Penning ionization was evidenced in $\mathrm{He}^{*}\left(2^{3} \mathrm{~S}\right)-\mathrm{N}_{2} \mathrm{O}$ interaction by observing fluorescence spectrum [46]. Consequently, both autoionizing states Rydberg states converging to $\mathrm{D}^{2} \Pi$ and the $\sigma$ shape resonance must be taken into account in Penning ionization of $\mathrm{CO}$ molecule by $\mathrm{He}^{*}\left(2^{1} \mathrm{~S}\right)$ atoms.

\section{References}

[1] Hotop H. and Niehaus A., Z. Phys. 228 (1969) 68.

[2] Rutherford G.H., Soletsky P.A., Bryan W.H., Dunning F.B. and Walters G.K., Phys. Rev. A 46 (1992) 230.

[3] Yoshida H., Ukai M., Kawamura H., Kouchi N. and Hatano Y., J. Chem. Phys. 97 (1992) 3289.

[4] Djerad M.T., Gounand F., Kumar A. and Cheret M., J. Chem. Phys. 97 (1992) 8334.

[5] Hotop H. and Hübler G., J. Electron Spectrosc. Relat. Phenom. 11 (1977) 101.

[6] Goy W., Morgner H. and Yencha A.J., J. Electron Spectrosc. Relat. Phenom. 24 (1981) 77.

[7] Goy W., Kohls V. and Morgner H., J. Electron Spectrosc. Relat. Phenom. 23 (1981) 383.

[8] Leisin O., Morgner H. and Müller W., Z. Phys. A 304 (1982) 23.

[9] Benz A. and Morgner H., Mol. Phys. 57 (1986) 319.

[10] Lescop B., Ben Arfa M., Le Coz G., Cherid M., Sinou G., Le Nadan A. and Tuffin F., Chem. Phys. Lett. 252 (1996) 327.

[11] Cermak V., J. Electron Spectrosc. Relat. Phenom. 9 (1976) 419.

[12] Kischlat W. and Morgner H., Z. Phys. A 312 (1983) 305.

[13] Yencha A.J., Electron Spectroscopy theory thechniques and application, Vol. 5, C.R. Brundle and A.D. Baker, Eds. (Academic Press, New York, 1984) p. 197.

[14] Hotop H. and Niehaus A., Int. J. Mass Spectrom. Ion Phys. 5 (1970) 415.

[15] Yee D.S.C., Stewart W.B., McDonald C.A. and Brion C.E., J. Electron Spectrosc. Relat. Phenom. 7 (1975) 93.

[16] Tuffin F., Le Coz G. and Peresse J., C. R. Acad. Sci. (Paris) 291 (1980) 141.

[17] Ohno K., Mutoh H. and Harada Y., J. Am. Chem. Soc. 105 (1983) 4555.

[18] Harada Y., Ohno K. and Mutoh H., J. Chem. Phys. 79 (1983) 3251.

[19] Siska P.E., Rev. Mod. Phys. 65 (1993) 337.

[20] Richardson W.C. and Setser D.W., J. Chem. Phys. 58 (1973) 1809.

[21] Lescop B., Ben Arfa M., Cherid M., Le Coz G., Sinou G., Le Nadan A. and Tuffin F., J. Phys. B: At. Mol. Opt. Phys. 30 (1997) 1241.

[22] Wannberg B., Nordfors D., Tan K.L., Karlsson L. and Mattsson L., J. Electron Spectrosc. Relat. Phenom. 47 (1988) 147.

[23] Ogawa M. and Ogawa S., J. Mol. Spectrosc. 41 (1972) 393.

[24] Codling K. and Potts A.W., J. Phys. B: At. Mol. Opt. Phys. 7 (1974) 163.

[25] Plummer E.W., Gustafsson T., Gudat W. and Eastman D.E., Phys. Rev. A 15 (1977) 2339 . 
[26] Wu C.Y.R., J. Chem. Phys. 77 (1982) 1179.

[27] Carbonneau R. and Marmet P., Can. J. Phys. 51 (1973) 2202.

[28] Erman P., Rachlew-Källne E. and Sorensen S.L., Z. Phys. D 30 (1994) 315.

[29] Ehresmann A., Machida S., Ukai M., Kameta K., Kitajima M., Kouchi N., Hatano Y., Ito K. and Hayaishi T., J. Phys. B 29 (1996) 3629.

[30] Stephens J.A., Dill D. and Dehmer J.L., J. Phys. B: At. Mol. Opt. Phys. 14 (1981) 3911.

[31] Siggel M.R.F., Hayes M.A., McDonald M.A., West J.B., Dehmer J.L., Parr A.C., Hardis J.E., Iga I. and Tiit V., J. Chem. Phys. 96 (1992) 7433.

[32] Tuffin F., Le Coz G. and Peresse J., J. Phys. Lett. France 40 (1979) 271.

[33] Ben Arfa M., Le Coz G., Sinou G., Le Nadan A., Tuffin F. and Tannous C., J. Phys. B: At. Mol. Opt. Phys. 27 (1994) 2541.

[34] Dugan J.L.G., Richards H.L. and Muschlitz E.E., J. Chem. Phys. 46 (1966) 346.

[35] Merz A., Müller M.W., Ruf M.W., Hotop H., Meyer W. and Movre M., Chem. Phys. 145 (1990) 219.

[36] Yencha A.J., Ruf M.W. and Hotop H., Z. Phys. D 21 (1991) 113.

[37] Yencha A.J., Ruf M.W. and Hotop H., Z. Phys. D 27 (1993) 131.

[38] Ruf M.W., Yencha A.J., Hotop H., Movre M., Kerner C., Zillig S. and Meyer W., Z. Phys. D 37 (1996) 219.

[39] Nicholls R.W., J. Phys. B: At. Mol. Opt. Phys. 2 (1968) 1192.

[40] Yencha A.J., Ganz J., Ruf M.W. and Hotop H., Z. Phys. D 14 (1989) 57.

[41] Lavendy H., Robbe J.M. and Flament J.P., Chem. Phys. Lett. 205 (1993) 456.

[42] Carlsson-Göthe M., Wannberg B., Falk F., Karlsson L., Svensson S. and Baltzer P., Phys. Rev. A 44 (1991) R17.

[43] Baltzer P., Lundqvist M., Wannberg B., Karlsson L., Larsson M., Hayes M.A., West J.B., Siggel M.R.F., Parr A.C. and Dehmer J.L., J. Phys. B: At. Mol. Opt. Phys. 27 (1994) 4915.

[44] Honjou N. and Yarkony D.R., J. Phys. Chem. 89 (1985) 44.

[45] Nakatsuji H., Chem. Phys. Lett. 177 (1991) 331.

[46] Tokue I., Kudo T. and Ito Y., Chem. Phys. Lett. 199 (1992) 435. 